\title{
Sun Glint Manifestation at Evaluating the Black Sea Water Optical Parameters Using Satellite Measurements
}

\author{
V.S. Suetin, S.N. Korolev, A.A. Kucheryaviy \\ Marine Hydrophysical Institute, Russian Academy of Sciences, Sevastopol, \\ Russian Federation
}

\begin{abstract}
The problem of effective usage of satellite-derived remote-sensing data is considered. Modern ocean color instruments, improved optical models and data processing algorithms provide the possibilities to estimate marine inherent optical properties in routine operational mode. To obtain more reliable quantitative information it is necessary to take into account the dependencies of the results of satellite measurements on the influence of various factors. Sun glint is one of these factors. Typical examples of sun glint manifestations are considered in the results of the Black sea water optical parameter evaluation using the data of the MODIS NASA satellite instrument. The application of the specially selected representative data and the comparative analysis of the joint data obtained by SeaWiFS and MODIS instruments, provided the certain interpretation of these examples. It was found that even moderate sun glint can produce significant errors in chlorophyll $a$ concentration and light absorption coefficients by phytoplankton and yellow substance if the GIOP Generalized ocean color Inversion model for retrieving marine inherent Optical Properties) complex technique is applied. Errors in the spectra of total absorption and backscattering coefficients are smaller, but also clearly expressed. At the same time the results of applying the chlorophyll $a$ content traditional calculation algorithm are resistant to the glint effect.
\end{abstract}

Keywords: satellite remote sensing, the Black Sea, sun glint, optical characteristics, chlorophyll $a$.

DOI: 10.22449/1573-160X-2016-3-47-56

(C) 2016, V.S. Suetin, S.N. Korolev, A.A. Kucheryaviy

(C) 2016, Physical Oceanography

Introduction. Data from the SeaWiFS and MODIS optical instruments operating in space can be useful in solving many scientific and practical problems associated with the research and control of different processes of the marine water state variability $[1,2]$. The high resolution satellite equipment registers the radiation of different wavelengths of the visible spectrum outgoing in the space. At the same time the systematic global observations over a wide band with $1 \mathrm{~km}$ spatial resolution are carried out. The obtained data and its processing results applying the unified techniques are accumulated in the NASA archives available at the public free access at (http://oceancolor.gsfc.nasa.gov/).

For effective application of such data, it's necessary to understand correctly their authenticity and take into account the effect of various factors it can depend on. Sun glint is one of them [3].

The glint leads to the total reflectance increase of the sea - atmosphere system registered by the satellite instrument. It depends on the sea surface roughness, the near-water wind speed, the angular survey structure and sea illumination by the solar beams, as well as on the optical properties of the atmosphere. The angular structure is determined by the instrument design features, the satellite's orbit and the changes in position of the sun in the heaven depending on the time of day and calendar date of the survey.

The glint is variously manifested in the measured radiation of different wavelengths. Therefore, the effects associated with it can lead to great errors in determination of the sea parameters applying complex methods such as, for example, the generalized ocean color inversion model for retrieving marine inherent optical properties (GIOP) [4].

In order to study the issues arising in this case we are to consider the examples of the results of the Black Sea joint observations by SeaWiFS and MODIS 
instruments. MODIS data used below was obtained by the instrument installed on the Aqua satellite. For a long time period MODIS and SeaWiFS operated independently on two satellites with different orbital parameters. The instruments captured overlapping sea areas at different angles with a small time difference.

Due to the structural features of these instruments the intensity of the sun glint manifestations has a significant difference in their readings. To weaken the glint effects SeaWiFS is equipped with mechanism for scan plane tilting in the direction opposite to the sun. MODIS does not have such a mechanism, so its results are more susceptible to the glint effects. Comparison of the data from the aforementioned instruments allows understanding the basic rules of the manifestations of the glint effects on the results of satellite observations.

Test material. During processing of the satellite instrument readings the parameters characterizing the properties of the atmosphere and sea upper layer water are determined. First of all, these are the sea surface remote-sensing reflectance $R_{\mathrm{rs}}(\lambda)$ for a number of wavelengths $\lambda$, the concentration of chlorophyll $a$, the optical thickness of the aerosol atmosphere component $\tau_{a}$ for the reference wavelength $\lambda_{0}$, Angstrom exponent $\alpha$, characterizing the spectral dependence of $\tau_{a}$. The computation results of the absorption $a(\lambda)$ and backscattering $b_{b}(\lambda)$ coefficients will be also considered below.

In addition to the basic parameters the satellite data processing products contain special supplementary indicators - the so-called flags, which can take the values of 0 or 1 . Flags 4 and 21 indicate the measurements with the probable sun glint manifestations. All other flags in the below considered test data have zero values. This indicates that the data contain no apparent defects or distortions, except those that may be associated with the glint. Full description of the system of flags can be found on the NASA website. The moderate sun glint area is marked by the flag having the number 21 . The flag number 4 indicates the high sun glint area. When processing the readings, marked with this flag, an additional glint distortionsensitive correction is carried out. To determine the numerical values of flags 4 and 21 and to perform the correction the model calculations related to the glint effects are fulfilled [3]. In this case the glint has the form of an additive supplement to the sea - atmosphere system reflectance measured in space and the required wind speed is set according to the accompanying meteorological data. At the formation stage of the final third level arrays (Level-3 format) flag 4 acts as a mask for rejection of the low practical use data.

The importance of the effects associated with the glint can be seen from the examples shown in Fig. 1. They are the results of the Black Sea observations by MODIS instrument on 09.06.2003 and 12.05.2007. In these dates according to MODIS data the glint region covers more than half the sea area and in its large part flag 4 are equal to 1 . In Fig. 1 location of the readings with zero scanning angle (subsatellite trajectory) is marked by the dashed lines. In relation to these lines the glint area is shifted to the west; with an increase of the scan angle the glint weakens and is completely absent near the swath edges.

Analysis of many other similar examples obtained by MODIS instrument at different years shows that in Fig. 1 the glint spatial distributions reflect the normal conditions in the Black Sea for the period from May to July - August. In early spring and in autumn the sizes of areas with flags 4 and 21 equal to 1 are reduced. In winter in the Black Sea observations both flags are almost always equal to 0 . The Fig. 1 examples are of particular interest as at these periods a significant part of the Black Sea has been cloud-free and provided by the results of almost simultaneous MODIS and SeaWiFS observations. For the below considered sea test areas the time difference between the two instruments doesn't exceed 15 minutes. 
In SeaWiFS data flags 4 and 21 are equal to 0 within the total sea area, except for its small part in the southwest, where for 09.06.2003 flag 21 is equal to 1 .
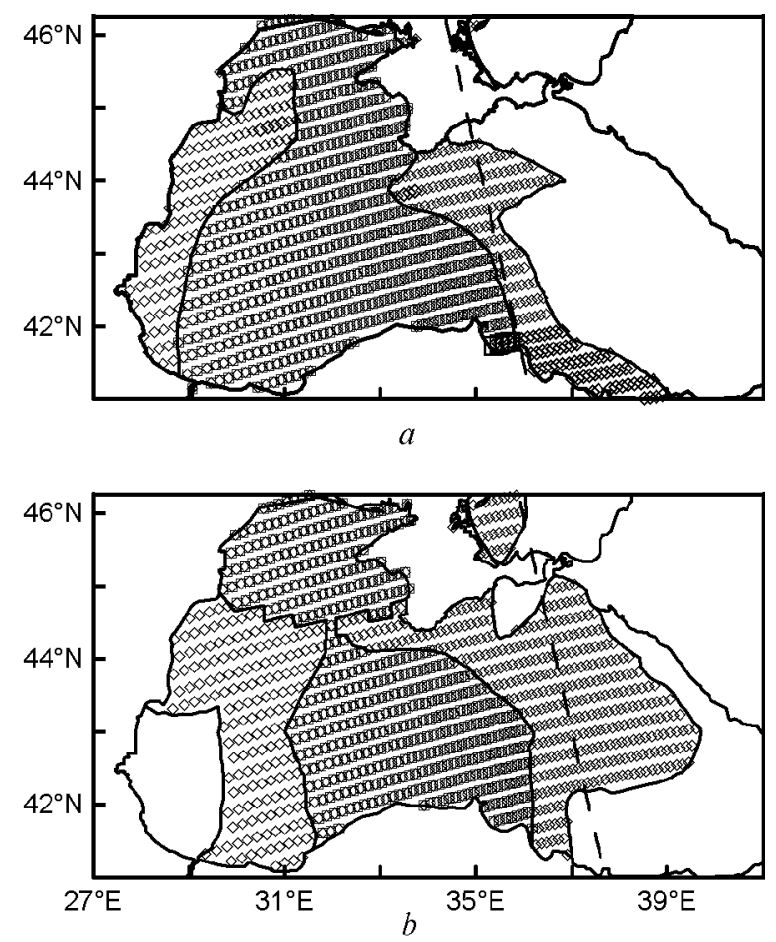

Fig. 1. Location of the areas where flags 4 and 21 are equal to 1 for the results of observation of the Black Sea by MODIS on 09.06.2003 (a) and 12.05.2007 (b). More dense hatching corresponds to flags 4 .

Features for 12.05.2007 results. Fig. 2 shows the results of determination of remote-sensing reflectance $R_{\mathrm{rs}}(\lambda)$ for $\lambda=412 \mathrm{~nm}$ and optical thickness of atmospheric aerosol component $\tau_{a}$ for $\lambda=\lambda_{0}\left(\lambda_{0}=865 \mathrm{~nm}\right.$ for SeaWiFS, $\lambda_{0}=$ $=869 \mathrm{~nm}$ for $M O D I S$ ) on the section $43.125^{\circ} \mathrm{N}$ from the data of two instruments. In the construction of these graphs the SeaWiFS GAC-format $4 \mathrm{~km}$ spatial resolution and the MODIS $1 \mathrm{~km}$ resolution readings selected from the band of $1.1 \mathrm{~km}$ width were used.

In addition to the standard processing NASA archive products the figure shows shows the results of special computations using SeaDAS program [5] without implementation the sun glint correction procedure to the MODIS readings.

In the eastern part of the section the glint is absent and there is a good match in the readings of the two instruments, while in the western part the glint effects in MODIS data lead to significant discrepancies. The glint effects are decreased by the correction procedure, but are not totally removed. In the further analysis only the standard data from the NASA archive, which this correction was applied in, is used. 

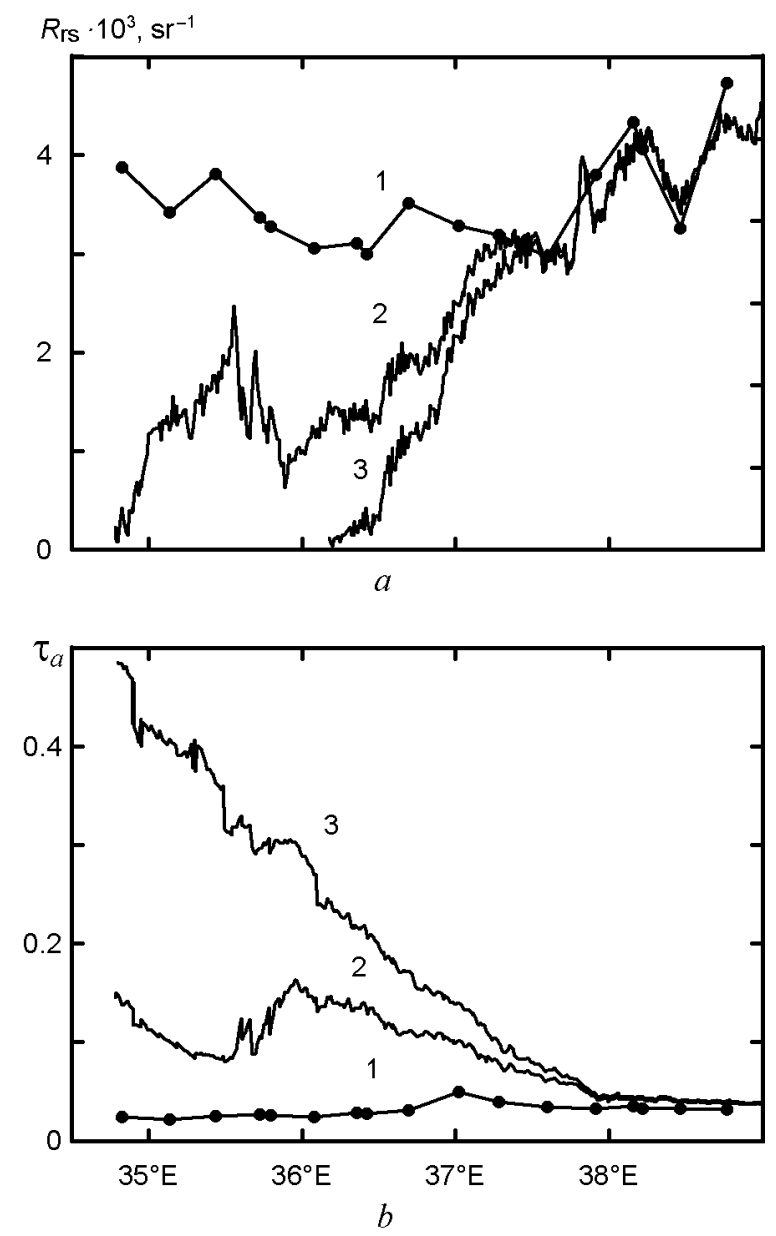

Fig 2. Results of determination of $R_{\mathrm{rs}}(412)$ ( $a$ ) and $\tau_{a}$ for $\lambda=\lambda_{0}(b)$ on the section at $43.125^{\circ} \mathrm{N}$ from the data of two instruments of 12.5.2007: 1 - SeaWiFS; 2 and 3 - MODIS (1 and 2 - standard products from the NASA archive, 3 - the variant of computations without sun glint correction)

According to NCEP data, the wind speed was within $2-6 \mathrm{~m} / \mathrm{s}$ in this sea area on 12.05.2007. For all Fig. 2 MODIS data flag 21 is equal to 1 . Flag 4 is equal to 1 to the west from $36.1^{\circ} \mathrm{E}$.

At $43.125^{\circ} \mathrm{N}, 36.7^{\circ} \mathrm{E}$ point $M O D I S$ has strictly vertical viewing direction. At the extremities of the graphs in Fig. 2 the scan angles are equal in absolute value and are about $16^{\circ}$. For the SeaWiFS data the sea observation angle measured from the vertical direction changed within the range of $22.3-38^{\circ}$.

Solar zenith angle for each instrument data remained practically unchanged and was equal to $\approx 28-31^{\circ}$. The relative azimuth angles (in absolute value) between the directions from the observation point to the Sun and to the satellite in the extreme western point in Fig. 2 graphs for MODIS and SeaWiFS data were equal to 133 and $86^{\circ}$, and in the extreme eastern point -40 and $44^{\circ}$, respectively. By analyzing the numerical values of the angles adduced here, it is easy to understand how the geometric conditions of observations affect the glint effects. 
SeaWiFS data show that in the considered sea area for 12.05.2007 the actual values of $\tau_{a}$ were low, and $R_{\mathrm{rs}}(\lambda)$ remained unchanged. Thus, we can draw a conclusion that the glint effect manifestations in the results of MODIS data processing are obviously unambiguous.

Interpretation of the spectral measurement results. The sun glint manifestations on the results of the determination of the spectral dependencies $R_{\mathrm{rs}}(\lambda)$ are illustrated by the examples in Fig. 3. These examples are specially selected for an obvious comparison of the results obtained from measurements by the two instruments in the glint-free and moderate glint conditions in MODIS data.

Tabl. 1 shows both the corresponding coordinates and the results of the determination of $\tau_{a}$ for $\lambda=\lambda_{0}$ and chlorophyll $a$ concentration in water. This value is designated here as $C_{a s}$. The NASA adopted traditional technique was used for its calculation [6]. The spatial position of the readings for 09.06 .2003 is schematically shown in Fig. 4. For 12.05.2007 it is easy to imagine according to Fig. 2 graphs. It should be noted that Fig. 4 does not reflect the real values of $\tau_{a}$ and $R_{\mathrm{rs}}(412)$, but the results of their calculations using MODIS data, distorted by the glint effect. These charts clearly demonstrate the same trend as Fig. 2 graphs. As a result of the glint effect with the growth of $\tau_{a}$ the value of $R_{\mathrm{rs}}(412)$ decreases.

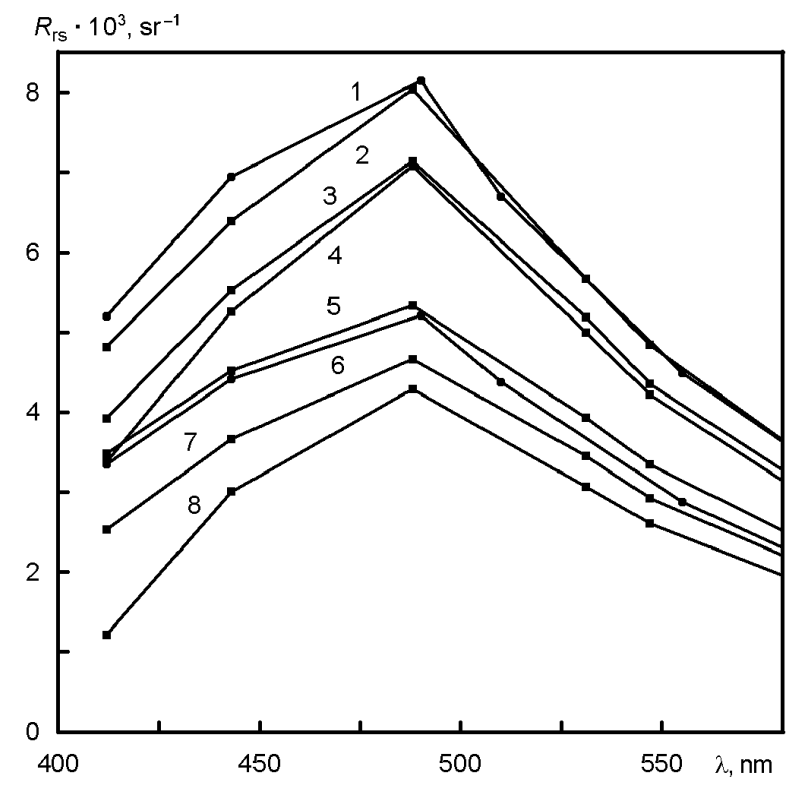

Fig. 3. Comparison of the spectral dependencies $R_{\mathrm{rs}}(\lambda)$, from the data of instruments MODIS and SeaWiFS in different conditions 9.06.2003 (1-4) and 12.05.2007 (5-8). The numbers of curves corresponds to the variants in Tabl. 1

The variants $1-4$ in Fig. 3 and Tab. 1 relate to 9.06.2003, the variants $5-8-$ to 12.05.2007. The variants 1 and 6 were obtained from SeaWiFS data, and the rest ones - from MODIS data. Only two examples are demonstrated here for SeaWiFS. There is no need to show the SeaWiFS data processing results for other readings, as they are almost equal to the variants 1 and 6 .

PHYSICAL OCEANOGRAPHY NO. 3 (2016) 
Table 1

Test Data Characteristics

\begin{tabular}{c|c|c|c|c|c|c}
\hline \multirow{2}{*}{ Variants } & \multirow{2}{*}{ Dates } & \multicolumn{2}{|c|}{ Coordinates } & \multirow{2}{*}{ Flag 4 } & \multirow{2}{*}{$C_{a s}, \mathrm{mg} \cdot \mathrm{m}^{-3}$} & $\tau_{a}$ \\
\cline { 3 - 5 } & & ${ }^{\circ} \mathrm{N}$ & ${ }^{\circ} \mathrm{E}$ & & \\
\hline 1 & 9.06 .2003 & 44.015 & 35.450 & 0 & 0.51 & 0.051 \\
2 & 9.06 .2003 & 44.015 & 35.460 & 0 & 0.53 & 0.047 \\
3 & 9.06 .2003 & 44.006 & 34.944 & 1 & 0.54 & 0.098 \\
4 & 9.06 .2003 & 44.393 & 35.461 & 0 & 0.52 & 0.118 \\
5 & 12.05 .2007 & 43.125 & 38.455 & 0 & 0.57 & 0.039 \\
6 & 12.05 .2007 & 43.128 & 38.466 & 0 & 0.52 & 0.033 \\
7 & 12.05 .2007 & 43.128 & 37.037 & 0 & 0.57 & 0.102 \\
8 & 12.05 .2007 & 43.122 & 35.137 & 1 & 0.54 & 0.101
\end{tabular}
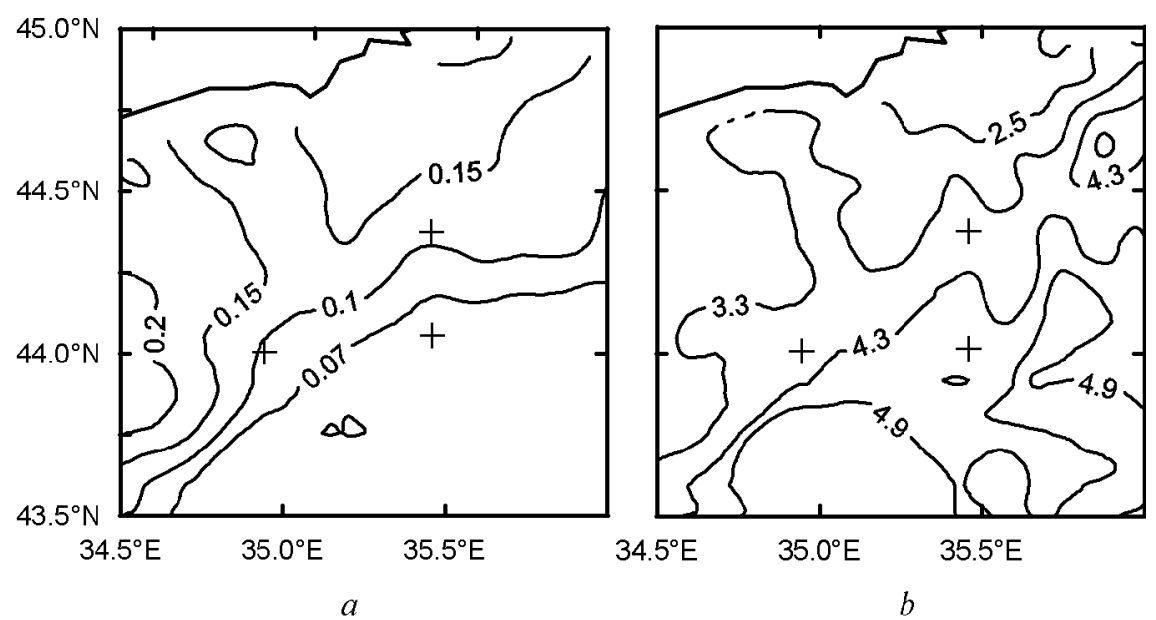

Fig. 4. Location of test readings (crosses) and spatial distributions of the results of determining of $\tau_{a}$ for $\lambda=869 \mathrm{~nm}(a)$ and $R_{\mathrm{rs}}(412) \cdot 10^{3} \mathrm{sr}^{-1}(b)$ from MODIS data of 9.06.2003

Variants 1 and 2 are the examples of measurements in the absence of the glint in the data of the two instruments for 9.6.2003. Similarly for 12.05.2007 such examples are variants 5 and 6 . In these examples, the spectra $R_{\mathrm{rs}}(\lambda)$, obtained by different instruments practically do not differ, $\tau_{a}$ is low and flag 4 is equal to 0 . While the equality of flag 21 to 1 should be ignored.

Variants 3 and 8 immediately demonstrate the effects directly related to the glint. For them, from the MODIS data flag 4 is equal to $1, \tau_{a}$ has elevated levels. From a comparison of these examples with the glint-free variants it can be concluded that the glint effect leads to $R_{\mathrm{rs}}(\lambda)$ decrease for all wavelengths. 
Variants 4 and 7 are interesting as for them from MODIS data flag 4 is equal to 0 , and yet they are also subjected to significant distortions due to the glint effect. This statement arises from a comparison of $R_{\mathrm{rs}}(\lambda)$ spectra in Fig. 3 and is confirmed by elevated level of $\tau_{a}$. Apparently, the zero values of flag 4 in these examples are conditioned by not quite an accurate setting of the wind speed needed for its determination.

The values of $\tau_{a}$ from Tab. 1 can serve as the intensity characteristic of the glint effects. Judging by SeaWiFS data, the aerosol optical thickness on both dates was low. Its values were close to the minimum ones observed in the Black Sea region. Based on their comparison with the results of $\tau_{a}$ estimation from MODIS data, we can conclude that there is a moderate sun glint manifested in the given examples. Note that the aerosol parameters are quite important as they are applied in the atmospheric correction of satellite measurements. And the accuracy of estimation of these parameters will influence on the accuracy of determination of the other parameters.

In Tab. 1 , the values of $C_{\text {as }}$ are practically the same for all variants. Consequently, the results of applying the chlorophyll $a$ content traditional calculation algorithm were resistant to the glint effect. However, it is well known that this algorithm often leads to large errors if applied to the Black Sea data processing $[7-10]$.

More accurate results can be obtained using such complex techniques as GIOP [4]. In contrast to the traditional algorithm when for the chlorophyll $a$ water content calculation the measurements from two spectral channels of satellite instrument are used, in GIOP technique the full range of channels is taken into account. This provides taking into account the effects associated with the independent variability of the main factors influencing the water optical properties.

In addition to the chlorophyll $a$ content, the spectral dependencies of the coefficients of absorption $a(\lambda)$ and backscattering $b_{\mathrm{b}}(\lambda)$ in the near-surface water layer are determined by GIOP. The variable components, describing the light absorption by phytoplankton $a_{\mathrm{ph}}(\lambda)$ and dissolved yellow substance $a_{\mathrm{dg}}(\lambda)$ (in combination with colored detrital matter), are also calculated.

GIOP is close to the techniques having previously been used in the analysis of the Black Sea space observations [8, $11-13]$. Recently, it is implemented in the NASA satellite data processing system.

Tab. 2 demonstrates the results of determination of these parameters for $R_{\mathrm{rs}}(\lambda)$ spectra shown in Fig. 3. NASA archives and SeaDAS calculations were used in the building-up of this table. Here $C_{a g}$ designates the chlorophyll $a$ concentration calculated by GIOP. The numbers of the test variants here are the same as in the Tab. 1. Fig. 5 shows the glint effects in the same sectional view as in Fig. 2.

In the glint-free cases (variants 1, 2 and 5, 6) from the data of two instruments almost identical results are obtained. They are quite consistent with the usual conditions for this season in the deep part of the Black Sea [11, 12, 14, 15]. Note that for some points there are no SeaWiFS data processing results in Tab. 2. These results do not differ from those obtained for variants 1 and 6 . 
Table 2

The Results of the Sea Water Optical Parameters and Chlorophyll $a$ Concentration Determination Applying GIOP Technique

\begin{tabular}{ccccccc}
\hline Variants & $a(443), \mathrm{m}^{-1}$ & $b_{\mathrm{b}}(443), \mathrm{m}^{-1}$ & $a_{\mathrm{ph}}(443), \mathrm{m}^{-1}$ & $a_{\mathrm{dg}}(443), \mathrm{m}^{-1}$ & $C_{a g}, \mathrm{mg} \cdot \mathrm{m}^{-3}$ \\
\hline 1 & 0.064 & 0.0087 & 0.012 & 0.045 & 0.22 \\
2 & 0.068 & 0.0088 & 0.011 & 0.051 & 0.20 \\
3 & 0.074 & 0.0081 & 0.008 & 0.060 & 0.14 \\
4 & 0.076 & 0.0079 & -0.001 & 0.071 & -0.02 \\
5 & 0.073 & 0.0064 & 0.016 & 0.050 & 0.29 \\
6 & 0.068 & 0.0059 & 0.012 & 0.050 & 0.22 \\
7 & 0.081 & 0.0058 & 0.006 & 0.069 & 0.12 \\
8 & 0.102 & 0.0054 & -0.029 & 0.124 & -0.52 \\
\hline
\end{tabular}

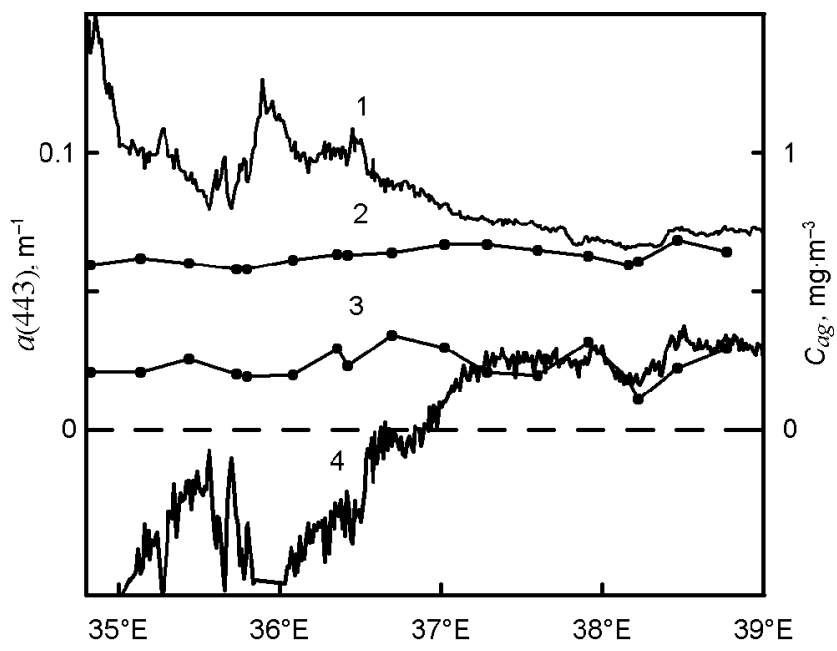

Fig. 5. Comparison of the results of MODIS (1 and 4) and SeaWiFS (2 and 3) data processing by GIOP technique, selected from the section along $43.125^{\circ} \mathrm{N}$. Absorption coefficient $a(443)-1$ and 2; chlorophyll $a$ concentration -3 and 4

In determining light absorbing components $a_{\mathrm{ph}}(\lambda), a_{\mathrm{dg}}(\lambda)$ and chlorophyll $a$ concentration, even moderate sun glint leads to large errors. The obtained $a_{\mathrm{ph}}(\lambda)$ and $C_{a g}$ are significantly lowered and may even have meaningless negative values. The errors in the total absorption $a(\lambda)$ are smaller but also clearly expressed. The glint results in an overestimation of $a(\lambda)$ and $a_{\mathrm{dg}}(\lambda)$. Applying GIOP to obtain reliable results it is necessary to have more accurate initial $R_{\mathrm{rs}}(\lambda)$ spectra.

Errors of $b_{\mathrm{b}}(\lambda)$ backscattering coefficient determination in these examples are minor, but it is fair to say that the main trend is the apparent reduction of $b_{\mathrm{b}}(\lambda)$. 
Conclusion. Thus, the considered examples make it possible to understand the basic features of sun glint effect on the data processing results of MODIS satellite instrument using the complex GIOP technique. Owing to a special selection of test measurements and comparison of SeaWiFS and MODIS instrument readings, the strict unambiguous interpretation of these examples is provided.

The obtained results show the importance of the glint effects that manifest not only MODIS instrument data, but also in other similar instruments without the mechanism for scan plane tilting. These include, for example, the modern instrument VIIRS presently operating in space. It turns out that the criteria for rejection of the distortions applied in a current operational processing of satellite measurements in NASA, does not fully ensure their elimination. That is why the final results of GIOP technique application in the NASA archive in Level-3 format, may contain serious errors.

The analysis performed will be useful in development of the more effective ways of satellite observation interpretation. Note that the high-intensity glint cases are easily selected and may be excluded from practical application. But in the moderate-glint cases the uncertainty appears requiring a more careful approach. These examples represent the major trends that characterize the sensitivity of the results of GIOP technique application with respect to the disturbances caused by the moderate sun glint.

Acknowledgements. The authors express their gratitude to the NASA GSFC satellite data processing group (http://oceancolor.gsfc.nasa.gov/) for the opportunity to use the empirical material.

\section{REFERENCES}

1. McClain, C.R., Feldman, G.C. \& Hooker, S.B., 2004, "An overview of the SeaWiFS project and strategies for producing a climate research quality global ocean bio-optical time series", Deep-Sea Res., Part II, no. 51, pp. 5-42.

2. 2008, "Why Ocean Colour? The Societal Benefits of Ocean-Colour Technology”, Ed. T. Platt, N. Hoepffner, V. Stuart and C. Brown, Reports of the International Ocean-Colour Coordinating Group, Canada, Dartmouth, IOCCG, no. 7, 141 p.

3. Wang, M., Bailey, S.W., 2001, "Correction of sun glint contamination on the SeaWiFS ocean and atmospheric products”, Appl. Opt., no. 40, pp. 4790-4798.

4. Werdell, P.J., Franz, B.A. \& Bailey, S.W. [et al.], 2013, “Generalized ocean color inversion model for retrieving marine inherent optical properties”, Appl. Opt., no. 52, pp. 2019-2037.

5. Baith, K., Lindsay, R., Fu, G. [et al], 2001, "SeaDAS: Data Analysis System developed for Ocean Color Satellite Sensors”, Eos Trans. AGU, no. 82, pp. 202.

6. O’Reilly, J.E., Maritorena, S. \& Mitchell, B.G. [et al.], 1998, “Ocean color chlorophyll algorithms for SeaWiFS”, J. Geophys. Res., no. 103, pp. 24937-24953.

7. Burenkov, V.I., Kopelevich, O.V. \& Sheberstov, S.V. [et al.], 2002, “Opticheskiy monitoring biologicheskogo i ekologicheskogo sostoyaniya Chernogo morya [Complex monitoring of the Black Sea biological and ecological condition]”, Kompleksnye issledovaniya severovostochnoy chasti Chernogo morya, pp. 417-432 (in Russian).

8. Burenkov, V.I., Kopelevich, O.V. \& Sheberstov, S. [et al.], 1999, "Bio-optical characteristics of the Aegean Sea retrieved from satellite ocean color data. The Eastern Mediterranean as a Laboratory Basin for the Assessment of Contrasting Ecosystems”, Ed. P. Malanotte-Rizzoli, V.N. Eremeev, Netherlands, Kluwer Academic Publishers, pp. 313-326.

PHYSICAL OCEANOGRAPHY NO. 3 (2016) 
9. Suetin, V.S., Suslin, V.V. \& Kucheryaviy, A.A. [et al.], 2001, “Osobennosti interpretatsii dannykh distantsionnykh opticheskikh nablyudeniy Chernogo morya s pomoshch'yu pribora SeaWiFS [Features of data interpretation of the Black Sea satellite remote sensing by SeaWiFS instrument]”, Morskoy gidrofizicheskiy zhurnal, no. 2, pp. 71-80 (in Russian).

10. Oguz, T., Ediger, D., 2006, “Comparison of in situ and satellite-derived chlorophyll pigment concentrations, and impact of phytoplankton bloom on the suboxic layer structure in the western Black Sea during May-June 2001”, Deep-Sea Res., Part II, no. 53, pp. 1923-1933.

11. Suetin, V.S., Suslin, V.V., Korolev, S.N. \& Kucheryaviy, A.A., 2002, “Otsenka izmenchivosti opticheskikh svoystv vody $v$ Chernom more letom 1998 goda po dannym sputnikovogo pribora SeaWiFS [Estimation of the variability of the water optical properties in the Black Sea in summer 1998 from satellite SeaWiFS instrument]”, Morskoy gidrofizicheskiy zhurnal, no. 6, pp. 44-54 (in Russian).

12. Suetin, V.S., Korolev, S.N., Suslin, V.V. \& Kucheryaviy, A.A., 2011, "Sravnitel'nyy analiz metodov opredeleniya opticheskikh parametrov Chernogo morya po dannym sputnikovykh izmereniy [Comparative analysis of the techniques for determining the Black Sea optical parameters the according to satellite measurements]”, Morskoy gidrofizicheskiy zhurnal, no. 2, pp. 33-42 (in Russian).

13. Suetin, V.S., Korolev, S.N. \& Kucheryaviy, A.A., 2014, “Ispol'zovanie sputnikovykh nablyudeniy dlya opredeleniya spektral'nykh zavisimostey opticheskikh kharakteristik vod Chernogo morya [Application of satellite observations for determining spectral dependencies of the Black Sea waters optical characteristics]”, Morskoy gidrofizicheskiy zhurnal, no. 3, pp. 77-86 (in Russian).

14. Churilova, T.Ya., Berseneva, G.P. \& Georgieva, L.V., 2004, “Izmenchivost' bioopticheskikh kharakteristik fitoplanktona $v$ Chernom more [The variability of the biooptical characteristics of phytoplankton in the Black Sea]”, Okeanologiya, vol. 44, no. 1, pp. 11-27 (in Russian).

15. Berseneva, G.P., Churilova, T.V. \& Georgieva, L.V., 2004, "Sezonnaya izmenchivost' khlorofilla i biomassy fitoplanktona $v$ zapadnoy chasti Chernogo morya [Seasonal variability of chlorophyll and phytoplankton biomass in the western part of the Black Sea]", Okeanologiya, vol. 44, no. 3, pp. 389-398 (in Russian). 